\title{
Batalhas públicas pela história nas redes sociais: articulações para uma educação histórica em direitos humanos
}

Public Battles for the History in the Social Networks: Connections Towards a Historical Human Rights Education

João Carlos Escosteguy Filho*

\section{RESUMO}

$\mathrm{O}$ artigo objetiva analisar visões sobre o passado em páginas autointituladas conservadoras, ou "de direita", na rede social Facebook. Pressupomos que, nos últimos anos, foi construída uma relação direta entre crescimento das redes sociais e ascensão de certa visão de mundo "de direita" sobre o passado que embasa projetos de sociedade no Brasil. Com base nas propostas da história pública $\mathrm{e}$ da educação em direitos humanos, e focando na análise de postagens das páginas virtuais sobre um "tema sensível" específico, a dupla escravidão-racismo, pretendemos analisar de que maneira certa concepção de mundo conservadora se coaduna com uma perspectiva de passado que, dissolvendo o peso do ontem sobre o agora, acaba também anulando a densidade histórica necessária a uma atitude historiadora comprometida com qualquer projeto emancipatório de sociedade.

Palavras-chave: redes sociais; educação em direitos humanos; usos do passado.

\section{Abstract}

This article aims to analyze views about the past in conservative self-titled pages, in the social network Facebook. We start from the assumption that, in recent years, there has been built a direct relationship between the growth of social networks and the rise of a 'rightwing' worldview about the past that underlies social projects in Brazil. From the goals of public history and human rights education, and focusing on the analysis of a specific 'sensitive issue,' the pair slavery/racism, we intend to analyze how a certain conservative conception of the world fits certain perspective of the past that dissolves the weight of this past on the present and also ends up nullifying the historical density necessary for a historian attitude committed to any emancipatory project of society. Keywords: social networks; human rights education; uses of the past.

\footnotetext{
* Instituto Federal de Educação, Ciência e Tecnologia do Rio de Janeiro (IFRJ), campus Pinheiral, Pinheiral, RJ, Brasil. joao.filho@ifrj.edu.br
} 
As primeiras duas décadas do século XXI assistiram a diversas discussões sobre questões relacionadas à história-disciplina (ou história escolar) e à história-ciência (ou história acadêmica) no Brasil. Essas discussões atravessaram variados suportes de mídia e inúmeros espaços, do livro didático a cartas de leitores de jornais, da sala de aula aos corredores do Ministério da Educação. Ao longo desse período, pudemos visualizar nesses debates uma oscilação ideológica marcante: de pautas associadas ao campo progressista (ou "à esquerda", como esse campo é muitas vezes denominado), o pêndulo tem nos últimos anos girado com força para questões mais caras ao campo conservador (ou "à direita", mais amplamente falando). Este artigo pretende analisar um aspecto dessa movimentação em um local específico: visões sobre o passado brasileiro em páginas de direita nas redes sociais, notadamente o Facebook. ${ }^{2}$

A partir dessa apresentação genérica, explicitaremos, nas páginas que seguem, o caminho percorrido até aqui. Para tanto, este artigo está dividido em três partes. Na primeira, apresenta-se uma justificativa para o foco aqui proposto, bem como uma breve análise, que não pretende esgotar o tema, sobre algumas discussões que marcaram os primeiros 20 anos deste século, com foco especialmente para o curto período pós-2013. Na segunda, são apresentados alguns elementos da pesquisa realizada, explicitando-se melhor nosso objeto geral, as formas de percepção do passado no Facebook, centralmente em páginas autointituladas "de direita". Por fim, teceremos algumas considerações sobre os rumos que a pesquisa nos possibilitará seguir daqui em diante.

O contexto aberto pela aceleração da temporalidade política a partir das Jornadas de Junho de 2013, com maior inflexão a partir das eleições de 2014 e das disputas que levaram ao golpe jurídico-parlamentar de 2016, trouxe para primeiro plano midiático uma série de discussões sobre a história-disciplina e a história-ciência. Embora os significados dessa aceleração ainda estejam fervorosamente abertos à interpretação, indo desde aqueles que consideram Junho de 2013 como um momento de abertura a novas formas de luta até aqueles que consideram o movimento um ponto de inflexão do reacionarismo contemporâneo (Gohn, 2017, p. 31-81; Mattos, 2016, p. 93-103; Demier, 2017, p. 65-81), podemos afirmar que o processo aberto pelo questionamento do 
aumento das passagens de ônibus em São Paulo, que se avolumou a ponto de constituir o maior conjunto de manifestações do Brasil desde as Diretas Já e o Fora Collor, produziu uma onda que influenciou diretamente os processos político-sociais no Brasil dos anos seguintes, ainda sem data para terminar.

Dentre os principais elementos dessa onda, no turbilhão de propostas, reclames, manifestações de indignação e gritos oriundos das ruas, podemos identificar o irrompimento da história como aspecto constituinte da busca por sentido imediato às angústias daquele momento. Não à toa, uma profusão de imagens apelantes à história brotou naquele contexto, imagens tanto concretas quanto virtuais, indo dos cartazes que, fazendo eco a 1964, pediam intervenção militar, até as contraimagens que solicitavam mais aulas e livros de história para essas pessoas.

Dali em diante, com cada vez mais intensidade, as batalhas pelas interpretações do passado brasileiro, em especial aquelas associadas ao passado mais recente, arrojaram-se nos mais diversos espaços midiáticos, com destaque para frações hegemônicas da mídia tradicional, já tradicionalmente envolvidas na produção de escritas midiáticas da história pública organizadas em duas dimensões: a escritura do evento na cena pública, elaborando sentidos sobre o ocorrido "no momento da emergência no cotidiano", e, posteriormente, na "inscrição dessas ocorrências no tempo", transpondo a "efemeridade do presente" (Meneses, 2018a, p. 183-184). A novidade nessas batalhas interpretativas do passado foi a sua cada vez maior difusão por outros espaços midiáticos, notadamente as redes sociais, alçadas a novo espaço público de discussão que, aliás, influenciou decisivamente os rumos da política eleitoral nos dois últimos pleitos nacionais.

Boa parte dessas discussões e debates, é importante frisar, não nasceu nesse contexto recente. Ao invés, foi gestada com mais força ao longo de toda a primeira década do século XXI, em grande parte como resposta a políticas públicas que tocaram temas sensíveis de nosso passado recente e distante, como a promulgação da Lei 10.639/03, a expansão das políticas de cotas e, mais recentemente, os procedimentos levados adiante pelas Comissões da Verdade.

Em especial no que tange aos "temas sensíveis", uma série de obras, artigos em jornais e atuações nas redes sociais e na mídia tradicional, dentre outros, construiu marcos de interpretação para o passado brasileiro que surgem, esta é a hipótese com que trabalhamos, como resposta para os avanços de 
certas concepções consideradas "de esquerda" para a história em particular e para a educação em geral. Embora mais pesquisas sejam necessárias para traçar com precisão os fios desse levante, articulado ao que alguns autores têm nomeado "onda conservadora", alguns marcos se destacam nesse processo, como indica Meneses (2018, p. 159-184):

1) a divulgação de artigos e editoriais em jornais, especialmente em O Globo e na Folha de S. Paulo, que atacam e relativizam concepções sobre o passado presentes em livros didáticos, em especial a partir do ensino da Guerra Fria (caso dos textos de Ali Kamel ao Globo) e da ditadura (chamada "ditabranda" na Folha);

2) a publicação, a partir de 2009, dos Guias Politicamente Incorretos (da História do Brasil, da História da América Latina e da História do Mundo, além de outros temas não necessariamente históricos), inspirados em série americana que nasce do combate negacionista/revisionista à historiografia da escravidão e da Guerra Civil nos Estados Unidos;

3) o crescimento da fama de intelectuais, no sentido gramsciano - isto é, no sentido de sujeitos responsáveis pela construção homogênea de certa "visão de mundo" de classe ou grupo (Gramsci, 2004, p. 15-20) -, que se apresentam como expressão de uma "nova direita" e que se consideram a construção de visões sobre o passado parte integrante da formação de um novo consenso social (casos que vão de Olavo de Carvalho, atuante na grande mídia nos anos 1990 e 2000, e membro ativo das redes sociais no século XXI, e que chegam até iniciativas como o Brasil Paralelo);

4) por fim, movimentos como o Escola Sem Partido, cuja motivação originária era o combate a visões "de esquerda" (na prática, boa parte das concepções academicamente paradigmáticas) em sala de aula, associadas a uma ideia de "doutrinação". (Frigotto, 2017)

Em íntima conexão com esse fenômeno, a primeira década deste século viu nascer e expandir-se também um novo tipo de relacionamento humano, consubstanciado no crescimento das redes sociais, especialmente do Facebook, que se tornou espaço central para a promoção de conexões políticas, articulações identitárias, organizações sociais e elaboração de intervenções no debate público mais amplo, o que se pode perceber em ocasiões tão distintas quanto a Primavera Árabe de 2011 e as eleições nos Estados Unidos em 2016, bem como no Brasil, mais recentemente. Não seria exagero afirmar que, sem esse 
crescimento das redes sociais, dificilmente haveria essa configuração de forças de direita no atual espectro político brasileiro. Os principais intelectuais e movimentos liberal-conservadores-reacionários nascidos nos últimos anos surgiram ou se promoveram com base nas redes sociais e nos espaços de difusão midiática, como o YouTube. São exemplos os movimentos MBL, Vem pra Rua e Indignados Online, dentre outros, bem como os já citados Escola sem Partido e Brasil Paralelo, além de intelectuais como Olavo de Carvalho.

Reportagem do Estado de S. Paulo já indicava, em 2013, o volume de acessos à rede no país. Àquele momento, 78\% dos usuários de internet no Brasil acessavam algum tipo de rede social, percentual que alcançava 92\% entre os usuários mais jovens. O Facebook alcançava uma fatia de 73,5\% da audiência por aqui, atingindo 75 milhões de usuários e perdendo em números absolutos apenas para os Estados Unidos (“Em 2013...”, 2014). Em 2018-2019, mesmo com o aumento da concorrência frente a outras redes sociais, os números mostravam-se ainda mais avassaladores: o número de pessoas com acesso às redes sociais alcançou 140 milhões de usuários no país (em torno de 66\% da população), sendo o Facebook o preferido de 90\% delas, perdendo apenas para o YouTube, segundo pesquisas de mercado (Techtudo, 2019). E, mesmo com a mudança no "pódio" dos países com maior número de usuários (os Estados Unidos caíram para segundo e o Brasil, para terceiro; ambos ultrapassados pela Índia), o Brasil chegou ao número de 130 milhões de inscritos nessa rede social (Tecmundo, 2019).

Frente a esses números, é fundamental considerar a importância desses espaços virtuais (nem por isso menos reais) não apenas para ampliação e modificação das formas cotidianas de interação social, mas também para a expansão de espaços de discussão pública na contemporaneidade, assim como para a produção de interpretações sobre a sociedade - políticas, culturais, econômicas, mas também, e fundamentalmente para este trabalho, históricas. Afinal, como espaços centrais para a formulação, reformulação, difusão e enfrentamento entre diferentes visões do passado nos dias que seguem, consideramos as redes sociais em geral, e o Facebook em particular, como lócus indispensável para a compreensão de certas discussões pertinentes à construção das mais variadas frações da consciência histórica (Rüsen, 2001) de grupos sociais no Brasil atual (Scherer-Warren, 2006, p. 216-222; Medeiros, 2013, p. 27-33). Em outras palavras, consideramos o Facebook um espaço privilegiado para análise 
das batalhas públicas pelas quais a história passa nos dias atuais, em íntima conexão com o movimento de ascensão de certo conservadorismo que, para além da vitória eleitoral de 2018, objetiva constituir-se como ideologia hegemônica (Gramsci, 2006, p. 93-96) para o desenho futuro de certo projeto de Estado, nação e sociedade.

Junto a essas duas, digamos, arenas de combate apontadas (ascensão de certas frações de um liberal-conservadorismo que disputam visões sobre o passado, por um lado, e ascensão das redes sociais, notadamente o Facebook, como espaços onde essas disputas se alastram, por outro), é preciso considerar uma terceira dimensão dos debates sobre a história-disciplina e a história-ciência que grassou no Brasil dos últimos anos. Refiro-me à introdução formal e ampliação significativa das discussões concernentes ao campo da história pública, que vem, desde 2010 ao menos, se consolidando como esfera fundamental das relações entre as produções da história acadêmica, os desdobramentos da história escolar e as manifestações e significados da história para além desses dois conjuntos, abrangendo um conjunto de temáticas tão variadas quanto museus, mídias, história oral e, dentre outros, para os interesses deste trabalho, as próprias redes sociais (Mauad; Almeida; Santhiago, 2016).

Expressão polissêmica cujas origens remontam aos Estados Unidos dos anos 1970, voltada primeiramente para a ampliação das áreas de atuação profissional dos historiadores, a história pública tomou corpo no mundo anglófono, em especial Austrália, Inglaterra e Canadá, como uma forma de conceber a produção do conhecimento histórico para, com e pelo público (Santhiago, 2016, p. 90-91). Dada a dimensão dessa proposta, a história pública apresenta um volume potencial de ampliação democrática do conhecimento histórico comparado apenas aos riscos que comporta, que vão desde o de simplificação do passado até o de reiteração de lógicas hierárquicas acadêmicas, enxergando a mera transmissão dos conhecimentos produzidos nas universidades como objetivo máximo da publicização dos saberes sobre o passado, ressaltando o aspecto para o público da tríade acima (Rovai, 2018, p. 185-196).

Mas, como afirma Zahavi (2011, p. 57), "a história pública não deveria ter medo de abraçar a controvérsia”. Pelo contrário: tal como tem acontecido no Brasil, a prática da história pública pode contribuir significativamente para a autorreflexão sobre o campo, incluindo o próprio questionamento sobre as dimensões do "público" envolvidas na construção dos saberes sobre o passado. 
Afinal, dada a multiplicidade do conceito de "público", que pode articular-se a expressões tão variadas quanto "opinião pública", "interesse público", "serviço público" etc. (Liddington, 2011, p. 43-50), o "público” está longe de constituir entidade monolítica apartada das tensões sociais, muito pelo contrário: está envolvo em conflitos entre grupos com distintos interesses na articulação passado-presente-futuro, tornando a história pública uma arena na qual mobilizações e usos do passado conectam-se o tempo todo a projetos de sociedade em disputa. Para além do risco de uma "comercialização" do passado para puro entretenimento, portanto, que Sayer (2015) chamou de risco de "disneyficação" do passado, ainda temos de levar em conta os usos políticos desse passado. Dada a importância das redes sociais nas discussões públicas atuais no Brasil, analisar esse espaço a partir desses usos políticos é essencial.

Este artigo insere-se entre essas preocupações, com base em um questionamento considerado central para o entendimento dos modos como vemos a produção de visões sobre o passado atualmente: quais são os conteúdos históricos veiculados no Facebook em vinculação com as disputas atualmente travadas na política nacional? Em outras palavras: que conteúdos e visões sobre o passado auxiliam na construção de concepções de mundo conservadoras, alimentando ideologicamente os processos de construção de identidades políticas associadas ao espectro da direita? Para começar a responder a essas perguntas, foram analisadas páginas da rede social Facebook autointituladas "de direita", no período compreendido entre 2016 e 2017, buscando-se verificar que visões sobre o passado eram mobilizadas nas postagens e comentários ali produzidos.

Como eixo aglutinador de nossas preocupações, selecionamos postagens diretamente relacionadas à temática dos direitos humanos. Tal escolha não foi fortuita, pois consideramos que a discussão a respeito da educação em direitos humanos tem conexão direta não apenas com a história acadêmica, mas também com a história ensinada e com a história pública. Seguimos, assim, as considerações de Mello (2008, p. 131-144) e de Araújo (2008, p. 145-165) para as possibilidades de integração entre as preocupações do campo da história (tanto científica quanto pedagogicamente) e o campo da educação em direitos humanos.

A temática dos direitos humanos tem importância fundamental na configuração geopolítica e social destes tempos que correm, sendo alçada, segundo 
Alves (2015, p. 1-22), desde o fim da Guerra Fria, e ao lado da temática ambiental, à condição de "tema global”. Segundo Moyn (2010), os direitos humanos constituem a "última utopia", uma vez que ocuparam boa parte, se não a maior parte do espaço dedicado à produção de políticas da esperança, anteriormente concebidas hegemonicamente em termos socialistas/comunistas. E a importância dessa dimensão pode ser constatada até mesmo na profundidade das discussões em torno de seus significados. Afinal, é certo que os direitos humanos tornaram-se referência central desde aqueles defensores de certa concepção hegemônica, muito associada ao predomínio das potências ocidentais e aos usos políticos dos direitos humanos para crescimento de processos de intervenção e destruição dos princípios de autogoverno dos povos, mascarando-se, muitas vezes, os interesses econômicos e geopolíticos que estimulam os avanços militares - naquela direção que Eric Hobsbawm (2007) chamou de "imperialismo dos Direitos Humanos". Mas também é correto afirmar que os direitos humanos, compreendidos numa concepção crítica e intercultural, alcançaram as pautas centrais de movimentos progressistas e emancipatórios, levantando o escudo dos direitos humanos contra aqueles alimentados pelo neoliberalismo que se pretende hegemônico (Santos, 2014; 2016; Candau, 2008).

O próprio avanço das críticas aos direitos humanos, especialmente por aqueles que os restringem aos "humanos direitos", é um indicativo da importância que os direitos humanos adquiriram ao longo do último meio século. Associados no discurso político reacionário a uma pauta de "esquerda", os direitos humanos tornaram-se alvo central daqueles que, na reiteração das condições de exploração social que tanto marcaram a formação do Brasil, elegeram a violência como proposta para atendimento aos graves problemas sociais, retornando a questão social a caso de polícia.

A centralidade da temática dos direitos humanos justifica abordarmos os três pilares anteriores (crescimento das redes sociais, do discurso de direita e da história pública) sob essa ótica, uma vez que tanto o discurso conservador dominante quanto os espaços das redes sociais e as propostas da história pública são loci privilegiados também de discussão sobre os direitos humanos. Para além disso, e conectando-se às questões da história pública, é preciso considerar, como Araújo (2006), as imensas proximidades entre as preocupações da história como forma de conhecimento e as questões ligadas aos direitos 
humanos, especialmente a partir das conexões íntimas entre as preocupações do ensino de história e da educação em direitos humanos.

Esta última constitui uma expressão multifacetada que, via de regra, expande-se no contexto dos processos latino-americanos de redemocratização, como no Brasil da virada dos anos 1970 para 1980. Nas décadas seguintes, segundo as considerações de Candau (2012, p. 17-34), uma interpretação predominante associada à expressão passa a relacioná-la a três elementos fundamentais constituintes: a construção de uma educação voltada para a formação de sujeitos de direito, a de uma voltada para o favorecimento de processos de "empoderamento" e a de uma para o "nunca mais", viabilizando políticas de memória contra as tragédias do autoritarismo e da violência em especial no âmbito do "Sul" (Sacavino, 2009, p. 65-104). O último ponto, em especial, é de crucial importância para a discussão aqui proposta: um ensino de história para o "nunca mais", necessariamente comprometido com uma dimensão emancipatória da educação, articula-se intensamente com questões relacionadas à história pública, ampliando o espaço de ensino-aprendizagem sobre o passado a partir de saberes construídos coletivamente e em conflito direto com concepções conservadoras que atuem no sentido de restringir a dimensão libertadora e democrática que a educação em direitos humanos exige.

É com base nessas considerações que o presente artigo propõe uma análise das formas pelas quais o passado é apresentado em sínteses interpretativas meméticas no Facebook, articulando essa produção interpretativa a manifestações e posicionamentos relacionados à discussão sobre os direitos humanos na ótica da educação em direitos humanos. A categoria com a qual trabalharemos para analisar esses usos do passado é a de escravidão-racismo, abordando simultaneamente uma temática cara à questão dos direitos humanos e um tema sensível de fundamental importância para a compreensão do país. ${ }^{3} \mathrm{O}$ modo como construímos a seleção das páginas analisadas e dessa categoria de análise está na parte II deste artigo.

Consideramos aqui como hipótese central de trabalho que a ascensão de certa direita no país se deu associada a certo discurso sobre o passado nas mídias tradicionais e redes sociais, construído fundamentalmente como resposta às conquistas e aos avanços a respeito dos direitos humanos e da educação em direitos humanos nos espaços públicos brasileiros das últimas décadas - avanços e conquistas, é bom ressaltar, ainda absurdamente tímidos em nosso 
país -, articulando-se a um movimento globalmente mais amplo de ascensão de uma direita que se coloca fundamentalmente contra aspectos indissociáveis do próprio discurso pró-direitos humanos como tema global.

A história pública, nesse sentido, tendo como um de seus fundamentos a construção de conhecimentos e saberes sobre o passado a partir de "autoridades compartilhadas" junto ao público, não pode se furtar à própria reflexão sobre quais são esses públicos, como eles são delineados e recortados nas disputas políticas mais amplas e como se articulam esses recortes à construção de visões de mundo em disputa pela hegemonia. Nossa abordagem, assim, considera que as formas públicas de manifestação do discurso historiográfico, entendido em larga escala simplesmente como "escritas sobre o passado", estão inseridas em uma arena de conflitos pela hegemonia que impõe aos historiadores críticos, desejosos ou não de tanto, que se manifestem nesses combates pela história pública, não em busca da recuperação de uma autoridade acadêmica que talvez nunca tenham tido predominantemente, mas em busca da construção de discursos historiograficamente possíveis comprometidos com as questões que movem a própria educação em direitos humanos. Afinal, como quer Sacavino, a educação em direitos humanos é uma proposta eminentemente política, voltada à transformação social e à construção de uma cidadania substantiva, suficientemente forte para garantir a formação de sujeitos atuantes (Sacavino, 2009, p. 33-64). Exatamente o oposto do que essas visões conservadoras sobre o passado defendem, uma vez que, articuladas a propostas em torno do movimento Escola Sem Partido, por exemplo, pregam exatamente a despolitização do ensino de história e o esvaziamento da presença do político e da atitude transformadora sobre a construção dos conhecimentos e saberes em sala de aula e fora dela.

\section{II}

A pesquisa empírica a que este artigo se refere foi desenvolvida principalmente entre agosto de 2016 e julho de 2017. Seu corpus é formado por um total de cinco páginas, todas identificadas de alguma maneira à direita e que foram selecionadas a partir de alguns critérios básicos, sem pretensão de hierarquia entre eles. 
Em primeiro lugar, buscamos a presença, em seus nomes, de termos correntes presentes na afirmação identitária de grupos de direita no Facebook, caso de "opressor", ou "politicamente incorreto", dois epítetos que marcam a ascensão desse conservadorismo que vimos discutindo. Partimos do pressuposto que, nas discussões em redes sociais, esses termos representam eixos discursivos que concentram em si certa síntese propositiva desses grupos. Assim, "oprimir", por relação de ironia, inverte o sentido do conceito social que passa a ser identificado a "coisa de esquerda". Isto é, o termo "opressão", presente em análises das ciências humanas que buscam refletir sobre desigualdades perenes na sociedade, passa a ser identificado a um certo "mimimi", onomatopeia que recentemente vem servindo de caminho para descaracterização do discurso do outro, especialmente daqueles identificados ao campo progressista. Da mesma maneira, "politicamente incorreto" tornou-se símbolo de certa concepção de mundo (e também de certa concepção historiográfica, como se pode verificar nos "Guias") que busca romper tudo aquilo que é considerado "farsa de esquerda" sobre o passado e o presente sociais.

Em segundo lugar, buscamos páginas que tivessem amplitude no número de membros, buscando, dessa forma, analisar postagens que representassem interpretações historiográficas difundidas por vários tipos de canais, e não somente aqueles que contassem com maior número de "curtidas". Em outras palavras, partindo de um número referencial de mil membros, buscamos páginas que pudessem ter uma grande variedade de seguidores, de modo a tentar conectar fios interpretativos do passado ligando desde grupos virtuais menores até páginas mais robustas.

Por fim, a seleção contou com o olhar seletivo das bolsistas envolvidas, todas da educação técnica integrada ao nível médio, no campus do Instituto Federal em que o projeto se desenvolveu. Consideramos esse critério de fundamental importância, em que pese sua grande subjetividade, uma vez que o olhar das pesquisadoras levou em consideração a presença e o impacto das publicações por elas analisadas junto ao corpo discente do próprio campus. Em outras palavras, após reuniões preparatórias, leituras inicialmente desenvolvidas e discussões encaminhadas, foram selecionadas páginas que, no olhar subjetivo das bolsistas envolvidas, tinham alguma influência no corpo discente do campus do Instituto Federal referido, fosse pela reprodução de conteúdo nas páginas pessoais de Facebook desses discentes, fosse pela presença de 
argumentos similares entre interpretações veiculadas nas páginas e falas elaboradas em conversas e debates que envolviam os discentes. Cada bolsista envolvida no projeto ficou originalmente responsável pela pesquisa em três páginas de direita.

Ao longo da pesquisa, algumas páginas foram descartadas pelo pouco volume de informação que ofereciam. Outras foram banidas do Facebook ao longo do trabalho, sendo descartadas as postagens até ali selecionadas previamente. Por fim, chegamos a cinco páginas identificadas à direita, indicadas na Tabela $1:^{4}$

Tabela 1 - Lista de páginas do Facebook analisadas

para a temática escravidão-racismo:

\begin{tabular}{cc}
\hline Nome da página & Número de membros (nov. 2016) \\
\hline Índia Capitalista Opressora & 44.034 \\
\hline Desquebrando o Tabu & 638.864 \\
\hline Preto Opressor & 79.737 \\
\hline Sim, sou de Direita & 58.808 \\
\hline Politicamente Incorreta & 65.383 \\
\hline
\end{tabular}

Para a proposta deste texto, nosso foco recaiu sobre as postagens que construíssem ou difundissem interpretações sobre o passado brasileiro associadas à temática da escravidão-racismo. Entrelaçando a discussão aos debates sobre história pública e educação em direitos humanos, escolhemos essa temática por compreendê-la como um tema sensível e como um dos pilares da formação brasileira, assim como um dos grandes gargalos para atendimento do "nunca mais" proposto pela educação em direitos humanos.

As questões centrais, então, são simples de enumerar:

1) que visões sobre o passado-presente da escravidão e do racismo são veiculadas nas páginas selecionadas acima?

2) que usos do passado são mobilizados pelas páginas para construção de posicionamentos políticos no presente?

3) como podemos relacionar concepções/interpretações históricas difundidas pelas páginas e conflitos atuais no campo das discussões sociais? 
A resposta a essas questões passa pela percepção mais geral dos sentidos da história nas páginas de direita analisadas. Como analisamos em outro momento (Escosteguy Filho, 2019), três são as principais características constituintes da forma como o passado é compreendido nessas páginas. Em primeiro lugar, o predomínio de uma abordagem histórica centrada em certa concepção genérica de indivíduo, próxima de um individualismo metodológico. Em segundo lugar, uma ausência de problematização e contextualização da realidade social, resultando em uma conexão interpretativa mais direta entre um dado fato e sua significação social. Por fim, tais páginas dão muito pouco peso às influências do passado sobre o presente, indicando uma concepção histórica que dá muito menos lastro à história para compreensão do mundo atual, resultando em pouca ou ausente "densidade histórica" para as análises que propõem da realidade social.

É nesse quadro que temas mais específicos, como o caso de escravidão-racismo, podem ser compreendidos nas abordagens que são feitas do passado. A página "Índia Capitalista Opressora" é um bom exemplo disso. O próprio nome, incorporando a ideia de "opressão" como um valor positivo - isto é, como um elemento definidor de resistência ao que é entendido como "mimimi", ou "politicamente correto", da esquerda -, e o termo "Índia" junto a "Capitalismo" produzem um combinado que remete à possibilidade de uma relação identitária, associada ao elemento indígena, estar não "a serviço" da esquerda, mas da direita. Incorporando o que tem sido uma marca da prática política do campo progressista nas últimas décadas, exemplificado pela expansão de termos como "lugar de fala", a página inverte os sentidos da expressão e reafirma a conexão capitalismo-conservadorismo para, desse ponto de vista, apresentar uma visão do passado considerada mais "verdadeira”. Afinal, a falsificação histórica seria apanágio da esquerda.

No que tange à relação escravidão-racismo, a página abordou, ao final de outubro de 2016, a discussão sobre cotas raciais. Como podemos ver nas Figuras 1 e 2, a perspectiva conecta a questão presente a uma síntese interpretativa do passado que consideramos absolutamente comum nas páginas pesquisadas: 
Figura 1

Igualdade e cotas raciais

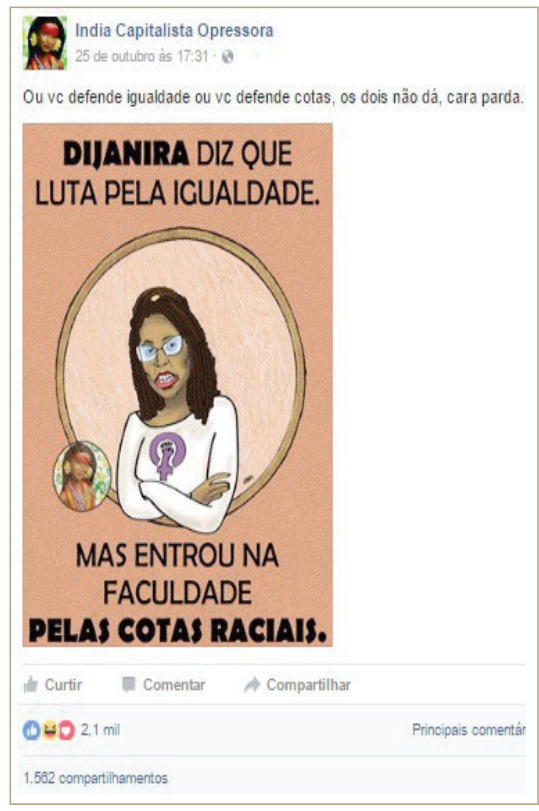

Figura 2

Cotas raciais e reparação histórica

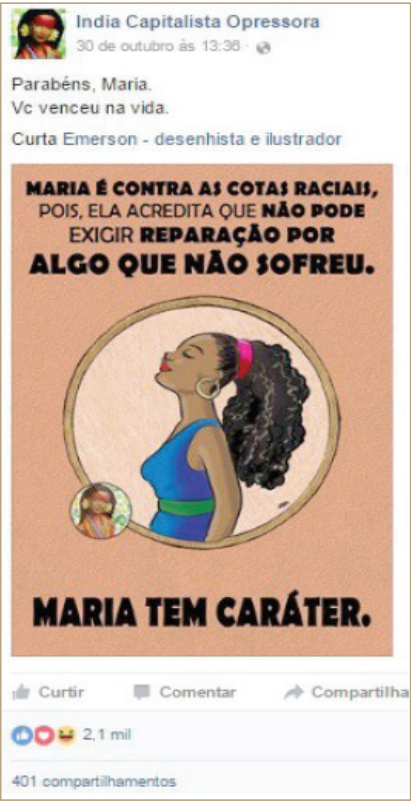

A conexão entre ambas as imagens dá o tom da forma como o passado irrompe no presente, ou como a questão da escravidão mantém-se como um "passado que não passa" (Pereira; Seffner, 2018, p. 14-33). Na Figura 1, as cotas são associadas a um elemento produtor de desigualdades, o que implica afirmar que a defesa da igualdade passa necessariamente pela ausência de quaisquer ações afirmativas que visem equalizar diferenças sociais. O social, aliás, é desconsiderado, e o conceito de igualdade restringe-se à acepção jurídica liberal que limita o alcance do próprio termo. Associando-se à Figura 2, novamente o tom individualista negador do peso do passado vem à tona: ser contra as cotas raciais (portanto, como visto, ser a favor da igualdade) significa compreender a inexistência de "dívida histórica", ou de necessidade de "reparação" em algum nível, já que a influência do ontem sobre o hoje aparentemente cessa no momento do óbito daqueles atingidos pelo peso do passado. Em outras palavras: "Maria", na Figura 2, é entendida puramente como ser individual despregado de qualquer conexão com o que veio antes de sua existência concreta. Nada acontecido no passado pode ter qualquer influência significativa 
sobre sua vida presente. As desigualdades sociais da contemporaneidade só podem ser explicadas na própria contemporaneidade. $\mathrm{O}$ passado perde poder explicativo e passa a limitar-se a mero antiquário repleto de curiosidades para os que vivem o tempo presente. Assim é que "vencer na vida" associa-se necessariamente à negação de qualquer poder explicativo à história para análise das condições de existência presente. Para a construção do futuro, do mesmo modo, apenas o que se faz no "hoje" pode contar.

Tal perspectiva redutora do peso do "ontem", como afirmamos, reduz a densidade histórica das interpretações sobre o passado. Interpretações sem densidade histórica seriam aquelas que diluem o passado em um discurso suficientemente ralo para anular as especificidades e as características que mantêm certos passados, notadamente os associados a "temas sensíveis", como passados que não passam, para retornar à expressão usada por Pereira e Seffner. Para os autores, um "passado que não passa" constitui

um passado vivo que se prende ao presente como residualidade ou como remanescência, constituindo o ser do paradoxo temporal. As aulas de história se põem a tomar como conteúdo de ensino e aprendizagem as residualidades do passado que não passam, que se estendem ao presente e que habitam a memória, constituindo experiências. [...] queremos pensar diversas dessas residualidades e remanescências, ou seja, sobrevivências do passado que se instalam na história e na memória e que insistem e nos fazem ver as experiências como virtualidade atuais. (Pereira; Seffner, 2018, p. 23-24)

Assim, tratar esses passados que não passam a partir de interpretações sem densidade histórica nos leva a desconsiderá-los para além da retórica discursiva. Eles não ganham força explicativa mais profunda. Não passam a constituir nossas demandas de memória e políticas públicas. Eles se tornam temas isolados do presente por uma barreira que esvazia seus significados mais intensos e os mantém confinados a um tempo apropriado a demandas políticas antiprogressistas, posto que a um tempo isolado de qualquer exigência do presente. A política (conservadora) dedica-se a isolar permanentemente do presente o passado que não quer ser apenas passado. E a maneira como as páginas aqui analisadas realizam essa operação é pela diluição de suas potencialidades. A Figura 3 ilustra uma das formas dessa operação. 
Figura 3 - Pureza Racial e Sociedade Miscigenada

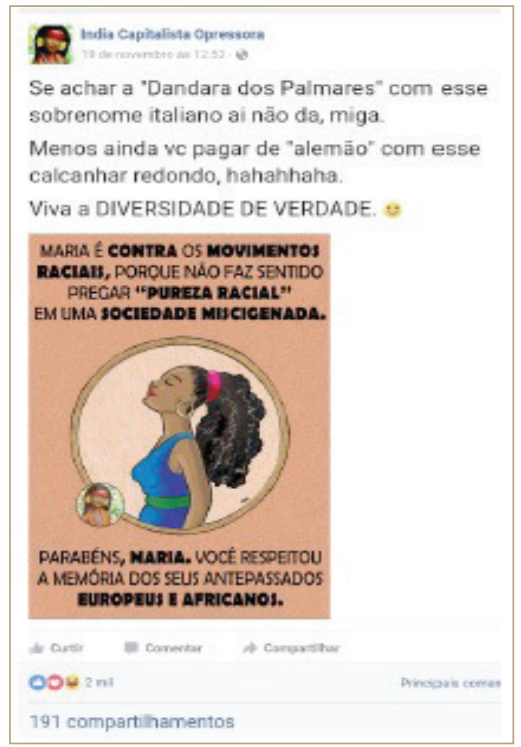

Se a política antiprogressista busca isolar do presente o passado que não passa, então o foco de crítica sobre os movimentos negros é um caminho importante para evitar que certa política progressista, associada à valorização da densidade histórica das interpretações do passado, possa ter sucesso. E para evitar o crescimento de movimentos negros, a desconsideração sobre a negritude é essencial, dissolvendo-a em uma abstrata "sociedade miscigenada" que recria a mística da "democracia racial", de "pais multicolorido", como barreira contra aqueles que defendem qualquer política reparadora dos males da escravidão e do racismo. Afinal, em um país no qual pretensamente se torna impossível dizer quem é negro e quem é branco, como atender a demandas de dívida histórica? Todos seríamos, brancos e negros, na verdade, apenas "pardos": descendentes da mistura de europeus, africanos e indígenas em tal dimensão que se tornaria impraticável, no limite, distinguir um brasileiro de outro. ${ }^{5}$

No fundo, portanto, as críticas à ideia de "dívida histórica" ou "reparação" dão o tom da maior parte das postagens analisadas sobre essa temática. A página "Desquebrando o Tabu", cujo nome foi pensado para se contrapor a uma outra considerada "esquerdista" ("Quebrando o Tabu”), não se furta a dar um tom racista a essa lógica, questionando indiretamente o porquê de negros 
pobres demandarem reparação, mas não os brancos originalmente pobres que não dependeriam de "favores" do Estado ou da sociedade (ver Figura 4).

Figura 4 - Dívida Histórica e Branquitude

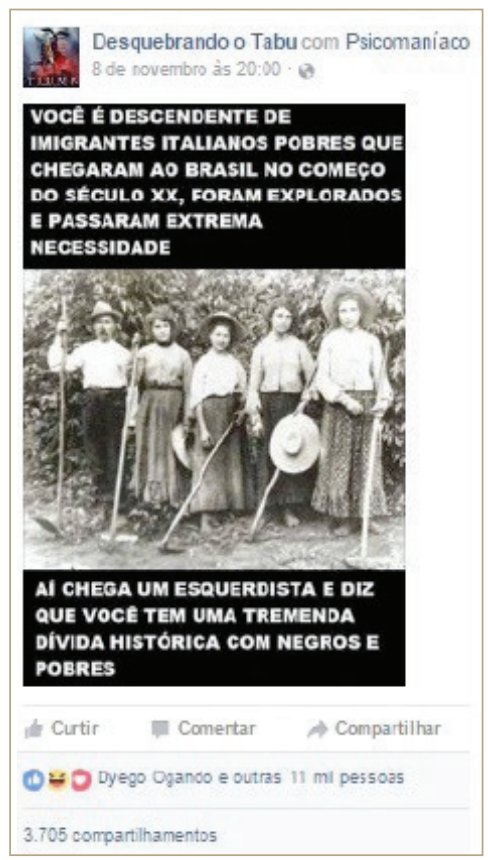

Novamente opera a diluição do passado a partir da redução da densidade histórica nas interpretações. Iguala-se o peso da escravidão ao peso das dificuldades dos imigrantes. Igualam-se grupos sociais em contextos, origens e sentidos distintos. A única conclusão possível é que um deles "venceu na vida", para usar expressão de imagem anterior, e os demais "não venceram" por conta de características internas a cada grupo, já que todos teriam passado pelos mesmos terrores da história. $\mathrm{O}$ mesmo movimento visa ao enquadramento do que seria uma "luta adequada", como se pode ver na Figura 5, da página "Sim, sou de Direita".

Para essas páginas, o passado não somente já passou para quaisquer discussões sobre o peso dele nas desigualdades atuais, como esse mesmo passado pode ser mobilizado para mostrar uma valorização da branquitude sobre a negritude. A dissolução das diferenças reduz qualquer análise do passado a um mero jogo de palavras (ver Figura 6). 
Figura 5 - Cotas e Branquitude

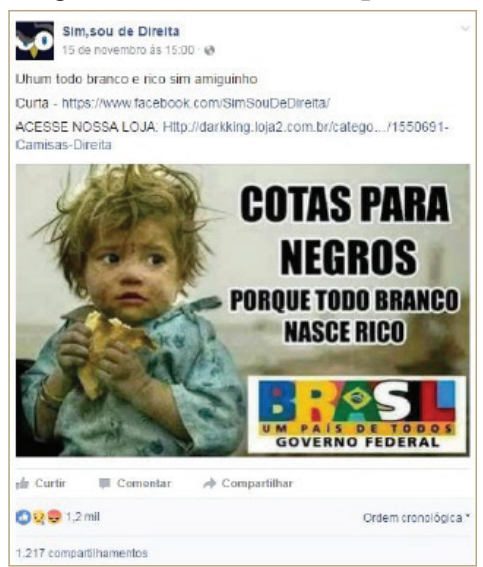

Figura 6 - Racismo e Branquitude

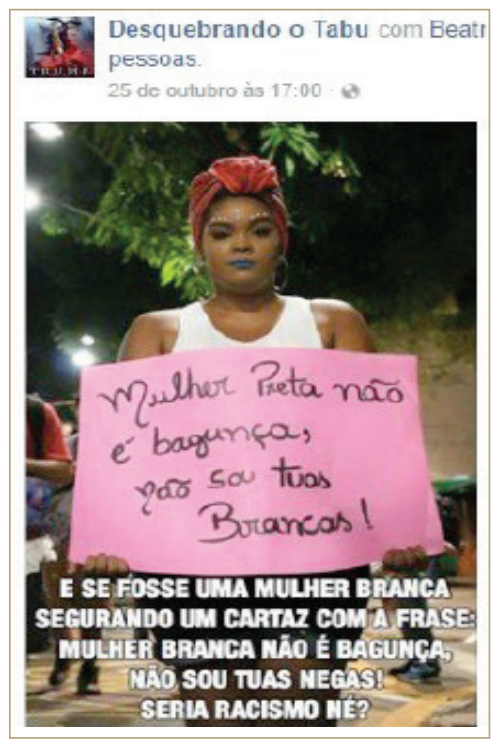

O racismo é restrito, nessa lógica, a uma definição dicionarizada que desconsidera absolutamente qualquer lastro histórico para o sentido das palavras no tempo presente. A inversão promovida pelo cartaz (que joga com uma histórica e corrente expressão racista, o "não sou tuas negas") é tratada pela página como tendo o mesmo impacto que o racismo que deseja combater. Não 
apenas qualquer reparação histórica é desnecessária, impraticável e racista, mas qualquer manifestação de valorização da negritude passa, nesse contexto, a ser igualmente associada ao racismo. O passado desgruda-se de qualquer poder explicativo sobre o presente.

Evidentemente, e aí se encontra o sentido mais profundo do racismo presente em tais interpretações, o passado pode ser instrumentalmente remobilizado quando é para a reafirmação de interpretações e padrões dominantes nas percepções sobre a história. Em outras palavras: se, por um lado, o movimento nas páginas de direita é predominantemente no sentido de esvaziamento da densidade histórica das interpretações quando o alvo são as explicações consideradas "esquerdistas", por outro lado o inverso pode ser realizado quando a intenção é reiterar normas interpretativas de certa historiografia que dá sustento a significados que combatam quaisquer intenções de lembrar os passados que não passam. O combate a interpretações mais críticas é acompanhado da reafirmação de historiografias conservadoras, atualizadas segundo os padrões indicados nos Guias e visões que discutimos na primeira parte deste artigo.

A "Desquebrando o Tabu" nos oferece um exemplo marcante dessa relação, notavelmente presente no contexto do Dia da Consciência Negra (Figura 7).

Figura 7 - Zumbi e Isabel

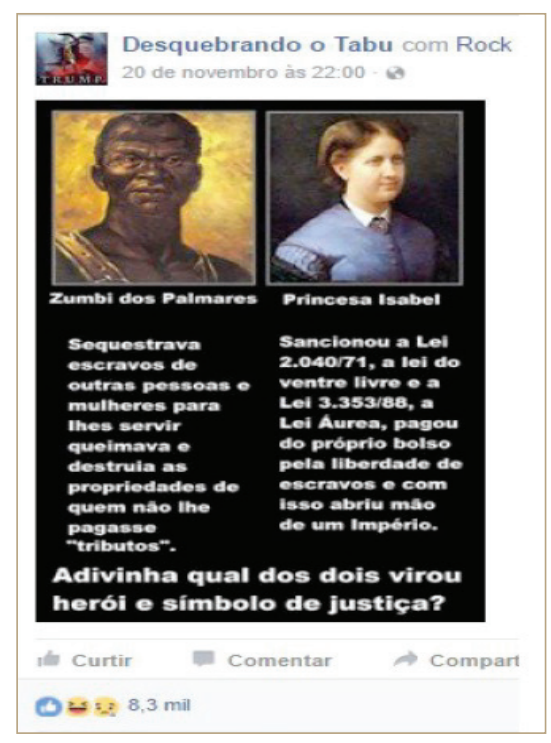


Tal exemplo tem marcado a reafirmação dessa historiografia em espaços que vão do Brasil Paralelo à eleição de um Orleans e Bragança à Câmara Federal. A redenção da redentora, até mesmo com base em interpretações forçadas e anti-históricas do passado, produz certo sentido negacionista a uma historiografia comprometida com questões sociais ligadas aos movimentos negros. As batalhas públicas pela história nas redes sociais trazem sentidos já superados academicamente para uma nova geração de brasileiros e brasileiras, apresentando-os como novidade, ou como reinstauração de uma verdade que as décadas de "doutrinação esquerdista" teriam assassinado.

A página Preto Opressor, que pelo próprio nome se coaduna com o que dissemos da Índia Capitalista Opressora, é outro espaço onde essa reiteração marca a disputa por sentidos relacionados ao passado (Figura 8).

Figura 8 - Zumbi e escravidão

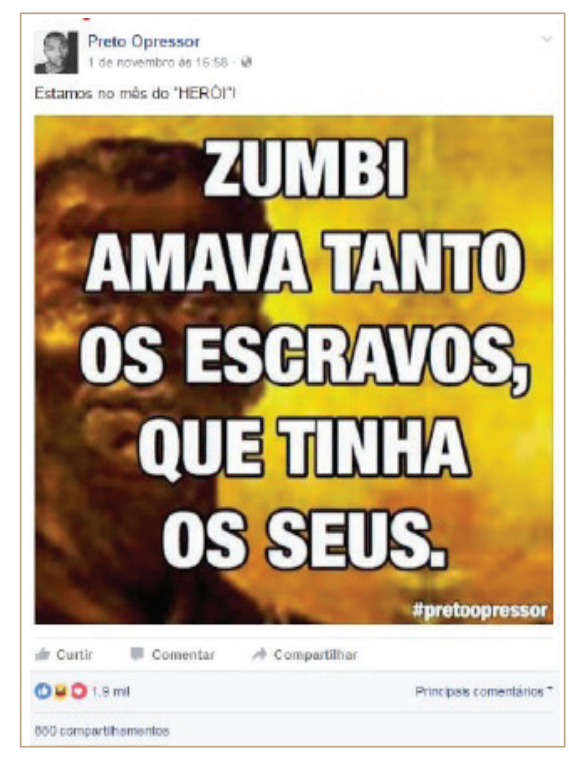

Zumbi é alçado a alvo de crítica menos pelo que foi em seu tempo de vida (o que implicaria levar em conta todas as discussões historiográficas sobre o "sujeito real") do que pelo que representou e representa perante movimentos que insistem na permanente discussão do passado que não passa. Ao negar a possibilidade de um passado não passar, reduzindo o alcance da história para 
explicar o presente, as páginas analisadas precisam, no mesmo movimento, também atacar processos de memória. A reafirmação do "país miscigenado", a reintrodução da redentora e a descaracterização dos símbolos da resistência negra são parte de um mesmo movimento que, ao negar o peso explicativo da história, acaba por centrar-se na construção de uma memória que, como concepção de mundo, orienta tanto ações presentes como projetos de futuro.

\section{III}

Mauad (2018, p. 228), analisando a letra do samba-enredo do G.R.E.S. Paraíso do Tuiuti, no Carnaval do Rio de Janeiro de 2018, explica aquilo que denomina "atitude historiadora": "a tomada de posse do passado comum como material para dar sentido ao presente e situar-se no fluxo do tempo futuro".

Tal concepção presente na historiadora aproxima-se da defesa que Rüsen (2007, p. 110-111) faz para a história: um tipo de conhecimento que possibilita orientação para a vida humana prática, sustentada por uma didática da história que possibilite certo aprendizado histórico como "ampliação da experiência do passado humano, aumento da competência para a interpretação histórica dessa experiência e reforço da capacidade de inserir e utilizar interpretações históricas no quadro de orientação da vida prática" - considerando-se, ainda, que "o saber histórico é um produto da experiência e da interpretação, resultado, pois, de síntese, e não um mero conteúdo pronto a ser decorado”. Em ambos os casos, a "atitude historiadora" refere-se ao sentido de direcionamento no tempo, de tomada dos sentidos de historicidade que permitem uma ampliação de nossa concepção de "ser" a partir do afastamento do excessivo presentista que estica o agora e elimina as relações entre ontem, hoje e amanhã (Hartog, 2013).

Nossa intenção, neste artigo, foi situar o debate no interior das redes sociais, consideradas como espaços centrais para essas articulações temporais nos debates públicos contemporâneos. Nosso foco na aproximação entre as preocupações da história pública e aquelas da educação em direitos humanos nos leva à compreensão de que qualquer atitude historiadora que permita uma plena tomada de sentido temporal e da historicidade de nosso "estar no mundo" exige que articulemos nossa reflexão histórica a uma dimensão emancipatória que não apenas se aproprie do passado - já que tal apropriação é sempre 
interpretativa -, mas que conduza essa apropriação a partir de uma lógica necessariamente crítica e reflexiva.

Em outras palavras, consideramos que uma tomada de posse do passado, para distanciar-se dos exemplos que vimos discutindo nas páginas anteriores, exige uma atitude historiadora conectada às preocupações da educação em direitos humanos, especialmente no tocante aos temas sensíveis e às exigências de construção de uma sociedade democrática de alta intensidade comprometida plenamente com o "nunca mais".

A alternativa, na era da diluição do peso do passado na explicação do presente, é, na "menos pior" das hipóteses, o retorno a uma concepção predominante (e falsa) de neutralidade na prática historiadora. Na "mais pior" das possibilidades, qualquer chance de uma construção nacional que passe pela democracia e pelos direitos humanos como valores centrais poderá estar irremediavelmente comprometida.

Consideramos que o caminho de superação desse risco exige a construção de uma "educação histórica em direitos humanos" que articule a dimensão dos saberes históricos acadêmicos e escolares a uma prática pública que se paute na incondicional defesa dos direitos humanos - ainda que essa expressão, como vimos, possa abarcar distintas percepções. É nessa ótica que uma história pública verdadeiramente democrática pode ser possível, uma vez que o marco definidor de uma visão historiograficamente adequada sobre o passado seria traçado numa dimensão ética da prática historiadora emancipatória e comprometida com os direitos humanos.

Para avançarmos nessa direção, que batalhas os historiadores comprometidos com uma prática emancipatória, articulados às preocupações de uma educação em direitos humanos voltada para o "nunca mais", precisam travar num ambiente cada vez mais relevante para a produção de concepções de mundo?

O primeiro passo é a ampla recuperação do caráter político do conhecimento histórico. Eis aqui um ponto no qual as disputas públicas nas redes sociais e alhures se entrelaçam às ameaças que o ensino escolar da história vem sofrendo nos termos postos por iniciativas como o Movimento Escola sem Partido (MESP). Para além do clima denuncista e da promulgação de projetos de lei que adeptos desse movimento visam implementar para construir travas à atuação docente em sala de aula (o que, em si mesmo, já é uma aberração 
didática inominável, para dizer o mínimo), o MESP ainda atua no sentido de redefinir significativamente as interpretações históricas paradigmáticas vigentes no país, presentes tanto em pesquisas acadêmicas quanto em livros didáticos e currículos nas escolas do Brasil. Uma breve observação das propostas do movimento deixa claro que não se trata da saudável discussão argumentativa que renova os saberes e o conhecimento histórico ao longo do tempo, mas, sim, de um retorno a interpretações já superadas pela historiografia, ao lado da adoção de concepções historiograficamente inaceitáveis sobre certos acontecimentos do passado (como a negação do caráter de "golpe" para 1964, feita por vários adeptos do movimento, por exemplo).

O aprofundamento sobre as interpretações históricas presentes no MESP exigiria outro artigo, mas as análises aqui apresentadas já mostram pontos em comum. O risco de que interpretações como essas disputem espaço nas salas de aula com outros conhecimentos e saberes nascidos da reflexão crítica e emancipatória é real. Os modos pelos quais as batalhas pelo passado serão travadas nas novas arenas públicas definirão a vitória ou derrota das batalhas pelo nosso próprio futuro.

\section{REFERÊNCIAS}

ALVES, José Augusto L. Os direitos humanos como tema global. [2003] 2. ed. São Paulo: Perspectiva, 2015.

ARAÚJO, Cinthia M. de. Educação em direitos humanos e o ensino de história: alianças possíveis. In: SACAVINO, Suzana. CANDAU, Vera Maria (org.). Educação em direitos humanos: temas, questões e propostas. Petrópolis: DP et alii ed., 2008. p. 145-165.

ARAÚJO, Cinthia M. de. Formando sujeitos: as alianças entre o ensino de História e a Educação em Direitos Humanos. 2006. Dissertação (Mestrado em Educação) Pontifícia Universidade Católica do Rio de Janeiro (PUC-Rio). Rio de Janeiro, 2006.

BOBBIO, Norberto. Direita e esquerda: razões e significados de uma distinção política. 2. ed. revista e ampliada. São Paulo: Ed. Unesp, 2001.

CANDAU, Vera Maria. Educação em direitos humanos no Brasil: gênese, desenvolvimento e desafios atuais. In: PAIVA, Angela R. (org.). Direitos humanos em seus desafios contemporâneos. Rio de Janeiro: Ed. PUC-Rio: Pallas, 2012. p. 17-34. 
CANDAU, Vera Maria. Multiculturalismo, educação e direitos humanos. In: SACAVINO, Suzana; CANDAU, Vera Maria (org.). Educação em direitos humanos: temas, questões e propostas. Petrópolis: DP et alii ed., 2008. p. 108-118.

DEMIER, Felipe. Depois do golpe: a dialética da democracia blindada no Brasil. Rio de Janeiro: Mauad X, 2017.

EM 2013, Brasil vira "potência" das redes sociais. O Estado de S. Paulo, 2014. Disponível em: http://economia.estadao.com.br/noticias/geral,em-2013-brasil-vira-potencia-das-redes-sociais-imp-,1111960. Último acesso em: 19 maio 2019.

ESCOSTEGUY FILHO, João Carlos. As redes sociais como sala de aula: possibilidades para uma Educação Histórica em Direitos Humanos. Revista Escrita da História, v. 6, n. 11, p. 85-114, 2019.

FERREIRA, Gabriela N.; BOTELHO, André (org.). Revisão do pensamento conservador: ideias e política no Brasil. São Paulo: Hucitec: Fapesp, 2010.

FRIGOTTO, Gaudêncio. Escola "sem" Partido: esfinge que ameaça a educação e a sociedade brasileira. Rio de Janeiro: Ed. Uerj: LPP, 2017.

GOHN, Maria da Glória. Manifestações e protestos no Brasil: correntes e contracorrentes na atualidade. São Paulo: Cortez, 2017.

GRAMSCI, Antonio. Cadernos do Cárcere. v. 1: Introdução ao estudo da filosofia. A filosofia de Benedetto Croce. 4. ed. Rio de Janeiro: Civilização Brasileira, 2006.

GRAMSCI, Antônio. Cadernos do Cárcere. v. 2: Os intelectuais. O princípio educativo. Jornalismo. Rio de Janeiro: Civilização Brasileira, 2004.

HARTOG, François. Regimes de historicidade: presentismo e experiências do tempo. Belo Horizonte: Autêntica, 2013.

HOBSBAWM, Eric J. Globalização, democracia e terrorismo. São Paulo: Companhia das Letras, 2007.

LIDDINGTON, Jill. O que é história pública? Os públicos e seus passados. In: ALMEIDA, Juniele R.; ROVAI, Marta G. de O. (org.). Introdução à História Pública. São Paulo: Letra e Voz, 2011. p. 31-52.

MATTOS, Marcelo B. De junho de 2013 a junho de 2015: elementos para uma análise da (crítica) conjuntura brasileira. In: DEMIER, Felipe; HOEVELER, Rejane. A onda conservadora: ensaios sobre os atuais tempos sombrios no Brasil. Rio de Janeiro: Mauad, 2016. p. 93-106.

MAUAD, Ana Maria. O carnaval da história pública. In: ALMEIDA, Juniele R.; MENESES, Sônia (org.). História pública em debate: patrimônio, educação e mediações do passado. São Paulo: Letra e Voz, 2018. p. 227-235.

MAUAD, Ana Maria; ALMEIDA, Juniele R.; SANTHIAGO, Ricardo (org.). História Pública no Brasil: sentidos e itinerários. São Paulo: Letra e Voz, 2016. 
MEDEIROS, Jackson da S. Considerações sobre a esfera pública: redes sociais na internet e participação política. Transinformação, Campinas, v. 25, n. 1, p. 27-33, jan./jul. 2013. Disponível em: http://www.scielo.br/pdf/tinf/v25n1/a03v25n1.pdf. Último acesso em 19/05/2015.

MELLO, Laura Cristina C. do A. Educação em direitos humanos e ensino de história: convergências e campo de possibilidades. In: SACAVINO, Suzana; CANDAU, Vera Maria (org.). Educação em direitos humanos: temas, questões e propostas. Petrópolis: DP et alii ed., 2008. p. 131-144.

MENESES, Sônia. Livros, leitores e internautas: os guias de história e os embates pelo passado através da mídia. In: ALMEIDA, Juniele R.; MENESES, Sônia (org.). História pública em debate: patrimônio, educação e mediações do passado. São Paulo: Letra e Voz, 2018. p. 159-184.

MENESES, Sônia. Qual a função da história pública em um país caracterizado por uma forte concentração midiática? In: MAUAD, Ana Maria; SANTHIAGO, Ricardo; BORGES, Viviane T. Que história pública queremos? São Paulo: Letra e Voz, 2018a. p. 181-187.

MOYN, Samuel. The Last Utopia: Human Rights in History. Cambridge: Belknap Press of Harvard University Press, 2010.

NETTO, Leila Escorsim. O conservadorismo clássico: elementos de caracterização e crítica. São Paulo: Cortez, 2011.

PEREIRA, Nilton M.; SEFFNER, Fernando. Ensino de História: passados vivos e educação em questões sensíveis. Revista História Hoje, São Paulo: Anpuh, v. 7, n. 13, p. 14-33, 2018. Disponível em: https://rhhj.anpuh.org/RHHJ/article/view/427/275. Acesso em: 30 maio 2019.

ROVAI, Marta G. de O. Publicizar sem simplificar: o historiador como mediador ético. In: ALMEIDA, Juniele R.; MENESES, Sônia (org.). História pública em debate: patrimônio, educação e mediações do passado. São Paulo: Letra e Voz, 2018. p. 185-196.

RÜSEN, Jörn. História viva: Teoria da História III: Formas e funções do conhecimento histórico. Brasília: Ed. UnB, 2007.

RÜSEN, Jörn. Razão Histórica: Teoria da História: os fundamentos da ciência histórica. Brasília: Ed. UnB, 2001.

SACAVINO, Susana B. Democracia e educação em direitos humanos na América Latina. Petrópolis: DP et alii ed.: De Petrus; Rio de Janeiro: Novamerica, 2009.

SANTOS, Boaventura de S. Direitos humanos, democracia e desenvolvimento. São Paulo: Cortez, 2016.

SANTOS, Boaventura de S. Se Deus fosse um ativista dos Direitos Humanos. 2. ed. São Paulo: Cortez, 2014. 
SAYER, Faye. Public History: A Practical Guide. Bloomsbury Academic, 2015.

SCHERER-WARREN, I. Redes sociais na sociedade da informação. In: MAIA, Rousiley; CASTRO, Maria Céres P. S. (org.). Mídia, esfera pública e identidades coletivas. Belo Horizonte: Ed. UFMG, 2006, p. 216-222.

TECHTUDO. Conheça as redes sociais mais usadas no Brasil e no Mundo em 2018. 2019. Disponível em: https://www.techtudo.com.br/noticias/2019/02/conheca-as-redes-sociais-mais-usadas-no-brasil-e-no-mundo-em-2018.ghtml. Último acesso em: 30 maio 2019.

TECMUNDO. Brasil é o terceiro país com mais usuários no Facebook. 2019. Disponível em: https://www.tecmundo.com.br/redes-sociais/139130-brasil-terceiro-pais-usuarios-facebook.htm. Último acesso em: 30 maio 2019.

ZAHAVI, Gerald. Ensinando história pública no século XXI. In: ALMEIDA, Juniele R.; ROVAI, Marta G. de O. (org.). Introdução à História Pública. São Paulo: Letra e Voz, 2011. p. 53-63.

\section{NOTAS}

${ }^{1}$ Doutor em História pela Universidade Federal Fluminense (UFF). Este trabalho contou com auxílio da Faperj e do CNPq, na forma de bolsas de iniciação científica.

2 Para os efeitos deste artigo, utilizaremos o termo "direita" em uma tripla acepção: em primeiro lugar, associado ao significado mais amplo de "conservador", que, não obstante a polissemia contida no termo, pode ser compreendido a partir de uma longa tradição que, remontando à Revolução Francesa, pode ser historicamente articulada a uma posição fundamentalmente contrarrevolucionária que, aliás, deitou raízes no Brasil desde o XIX, com especificidades (FERREIRA; BOTELHO, 2010, p. 11-13); em segundo lugar, e próximo ao primeiro, associado ao significado mais amplo de "liberal", como atualização burguesa da posição antiprogressista presente em Burke, cujas origens remontam, na Europa, ao combate às revoluções inspiradas pelos movimentos socialistas a partir de meados do oitocentos, e que no Brasil associou-se, especialmente, a uma tradição de combate anticomunista a partir, principalmente, dos anos 1920-1930 (NETTO, 2011, p. 40-69); em terceiro lugar, associado ao significado mais amplo de "reacionário", entendido aqui como próximo conceitualmente do que Bobbio (2001, p. 135) associou à extrema-direita antiliberal e anti-igualitária, saudosa do nazifascismo na Europa e que, no caso brasileiro, enxerga o passado ditatorial eivado de autoritarismo como porto seguro para cuja nostalgia, se pudessem, remeteriam a sociedade (não à toa, louvam os elementos autoritários do presente como mecanismos de sustentação social a serem mantidos inalterados, se não reforçados em suas características mais violentas). Essa distinção aqui descrita é puramente didática: na análise do artigo, o termo "direita" surgirá atravessado por características de todas as três acepções, constituindo, no limite, uma espécie de direita liberal-conservadora-reacionária. Assim, 
este artigo utilizará qualquer dos termos anteriores como semelhantes, uma vez que as proximidades nos interessam mais que as distinções que caracterizam cada um deles.

${ }^{3}$ Cabe uma pequena explicação sobre mudanças nos caminhos do trabalho. A pesquisa original completa, desenvolvida entre 2015 e 2017, elegeu inicialmente, como categorias de análise para as postagens, três temáticas relacionadas à questão dos direitos humanos: racismo, machismo e homofobia. Em 2017-2018, outras duas categorias foram acrescentadas: desigualdade social e violência de Estado. Nesse período entre 2015 e 2018, nosso foco não recaía apenas sobre páginas de direita, mas também sobre as de esquerda, buscando contrastar os modos pelos quais as páginas de cada espectro político abordavam as questões ligadas aos direitos humanos. A partir dessa seleção temática e das páginas selecionadas, analisamos, na pesquisa original, os modos pelos quais páginas de direita e de esquerda se posicionavam sobre as temáticas relativas aos direitos humanos, ao mesmo tempo que analisamos os argumentos que sustentavam essas posições a partir dos usos do passado feitos pelas páginas para justificarem seus pontos de vista. $\mathrm{O}$ foco neste artigo, contudo, por conta do limite de páginas, se restringe a apenas uma dessas categorias originais, o racismo. Em 2019 a pesquisa entrou em nova fase, com ênfase, agora, apenas sobre as interpretações históricas veiculadas em páginas de direita do Facebook. Das cinco categorias anteriores, duas foram escolhidas para continuarem nessa nova fase da pesquisa: o racismo e a violência de Estado, e suas denominações foram ampliadas para ressaltarmos a ênfase maior dada, a partir de então, sobre a questão histórica. Assim, utilizaremos, neste artigo, não a categoria "racismo", mas a categoria "escravidão-racismo", na qual o primeiro elemento do par ressalta o componente histórico da escravidão como tema sensível sobre o qual nosso esforço se debruça agora. À categoria "violência de Estado" acrescentou-se o conteúdo histórico sensível da ditadura, ficando, ao final, a categoria nomeada "ditadura militar-violência de Estado". Ambas as categorias articulam-se a uma questão de longa duração associada à lógica do autoritarismo como chave explicativa da história do Brasil. Para este artigo, mantivemos o material pesquisado na primeira fase da pesquisa (2015-2018), mas atualizamos o termo que nomeia a categoria para "escravidão-racismo", ao invés de apenas "racismo".

${ }^{4}$ Cabe ressaltar que a pesquisa completa, indicada na nota 3 , contou com um total de 150 postagens de 25 páginas diferentes. As cinco páginas aqui apresentadas, dentro da temática escravidão-racismo, constituem apenas um recorte da pesquisa maior.

${ }^{5}$ As contradições dessa linha de raciocínio, porém, avolumam-se no prolongamento dos debates sobre as postagens nas seções de comentários. Porém, por conta dos limites deste artigo, optamos aqui por restringir nossa análise somente às imagens em si, deixando a discussão sobre os comentários para trabalhos futuros.

Artigo recebido em 3 de maio de 2019. Aprovado em 24 de julho de 2019. 